Vol. 1 No. 1, Maret 2021, hlm. 73 - 80

DOI: $\operatorname{xxxxxxxxxxxxxxxxx}$

Available online at http:// jurnal.stmikroyal.ac.id/index.php/j-com

\title{
METODE CUSTOMER RELATIONSHIP MANAGEMENT UNTUK STOKIS LUXOR CABANG KISARAN BERBASIS WEB
}

\author{
Cici Paramita Panjaitan ${ }^{1}$, Iqbal Kamil Siregar ${ }^{2 *}$, Santoso $^{3}$ \\ ${ }^{1}$ Mahasiswa Prodi Sistem Informasi, STMIK Royal \\ ${ }^{2}$ Prodi Sistem Komputer, STMIK Royal \\ ${ }^{3}$ Prodi Manajemen Informatika, STMIK Royal \\ *email: iqbalkamilsiregar@ royal.ac.id
}

\begin{abstract}
Customer relationship management is a facility to strengthen relationship between companies and customers. CRM also establishes sales programs to build and manage close ties with customers so as not to move to other competitors. This thesis presents an increase in webbased CRM in Stockist Luxor Kisaran. Luxor Stockist is a business entity engaged in marketing herbal products, the system used is still with a manual system. The results of the fundamental method on the web obtained are managing customer data, product improvement, product sales, and consumer consultation facilities to respond to questions and suggestions from customers. This application uses the PHP and MYSQL programming language for the media to make it easier for customers to interact with the company. This application is expected to help companies strengthen the good word with customers in retaining customers and to get new customers.
\end{abstract}

Keyword :Customer Relationship Management, Marketing, Services, PHP language and MYSQL database

\begin{abstract}
Abstrak : Manajemen hubungan pada pelanggan ialah suatu fasilitas guna mempererat jalinan baik perusahaan dan pelanggan. CRM juga membentuk program penjualan guna membangun serta mengatur ikatan yang erat pada pelanggan agar tidak berpindah ke pesaing lain. Skripsi ini menyajikan peningkatan CRM berbasis web di Stokis Luxor Kisaran. Stokis Luxor merupakan badan usaha yang bergerak dalan pemasaran produk herbal, sistem yang digunakan masih dengan sistem manual. Hasil metode mendasar pada web yang didapat adalah mengatur data konsumen, peningkatan produk, penjualan produk, dan fasilitas konsultasi konsumen guna menanggapi pertanyaan maupun saran dari pelanggan. Aplikasi ini memakai bahasa program PHP dan MYSQL untuk media agar memudahkan pelanggan untuk berinteraksi dengan perusahaan.. Aplikasi ini diharap dapat membantu perusahaan dalam mempererat ikataan baik dengan pelanggan dalam mempertahankan pelanggan dan untuk mendapatkan pelanggan baru.
\end{abstract}

Kata Kunci:Customer Relationship Management,Pemasaran ,Pelayanan, bahasa PHP dan database MYSQL 
Vol. 1 No. 1, Maret 2021, hlm. 73 - 80

DOI: $\operatorname{xxxxxxxxxxxxxxxxx}$

Available online at http:// jurnal.stmikroyal.ac.id/index.php/j-com

\section{PENDAHULUAN}

Peran teknologi dalam mendukung proses bisnis sangat berdampak positif bagi suatu perusahaan, hal ini dikarenakan agar aktivitas pemasaran pada perusahaan menjadi lebih mudah dan lebih luas jangkauannya. Tantangan dalam bidang usaha sangat ketat dan sangat memerlukan langkah-langkah strategis untuk menghadapinya. Untuk itu setiap perusahaan harus meningkatkan mutu pelayanan terhadap pelanggannya. Kualitas layanan merupakan aspek penting dalam menjaga loyalitas pelanggan. Salah satu langkah guna menjaga loyalitas pelanggan dan melindungi kelangsungan hidup perusahaan dengan menjaga ikatan baik pada pelanggan, salah satunya adalah dengan menerapkan Customer Relationship Management (CRM) [1].

Stokis Luxor Cabang Kisaran bergerak dibidang pemasaran produk herbal. Stokis Luxor ini berlokasi di jalan Dr.Wahidin No.37 Kisaran. Stokis Luxor menerima pemesanan produk herbal, sampai saat ini sistem yang digunakan pada Stokis Luxor masih dengan sistem manual. Kemudian pada saat pelanggan ingin memesan produk, pelanggan hanya dapat memesan melalui via telepon, SMS atau harus datang ke Stokis Luxor. Permasalahan lainnya yaitu tidak adanya fasilitas yang dapat membantu pelanggan untuk melakukan interaksi dengan pihak Stokis dalam menyampaikan saran, kritik, dan pertanyaan. Stokis Luxor juga mengalami kesulitan dalam mengelola data pelanggan, data produk dan juga stok produk. Seiring dengan perkembangan teknologi, Stokis Luxor ingin bisnisnya dapat berkembang dengan menggunakan strategi bisnis yang berorientasi pada pelanggan.

CRM adalah suatu strategi perusahaan yang digunakan untuk memanjakan pelanggan agar tidak berpaling kepada pesaing lain dan berguna untuk mengetahui keperluan serta tingkah laku pelanggan pada saat memperluas jaringan pelanggan [2]. CRM ialah sebuah filosofi bisnis yang menggambarkan suatu strategi penempatan konsumen sebagai pusat proses, aktivitas dan budaya [3]. CRM juga sebagai media untuk menyatukan hubungan yang berkepanjangan bagi perusahaan dan pelanggan. Dengan memanfaatkan CRM, maka perusahaan tentu memahami segala sesuatu yang diinginkan dan yang dibutuhkan pelanggannya, strategi pengelolaan pelanggan, mulai dari proses pemasaran, hingga dengan fasilitas pelayanan yang bertujuan untuk meningkatkan kepuasan pelanggan.

CRM merupakan usaha yang melibatkan sumber daya perusahaan dalam menjalin kerjasama dengan pelanggan [4]. Tujuan CRM adalah untuk meningkatkan penghasilan dari kepuasaan pelanggan [5]. Oleh karena itu, CRM sangat tepat untuk diterapkan dalam badan usaha yang bergerak dibidang pemasaran salah satunya pada Stokis Luxor Cabang Kisaran.Dengan dibangunnya sistem tersebut, Stokis Luxor diharapkan dapat memberikan kualitas pelayanan yang baik, serta menjaga eksistensinya dalam bersaing dengan bisnis produk herbal lainnya.

\section{METODE}

Metode penelitian yang digunakan dalam penelitian ini adalah metode kualitatif. Metode kualitatif dilakukan dengan menggunakan teknik observasi dan teknik 
Vol. 1 No. 1, Maret 2021, hlm. 73 - 80

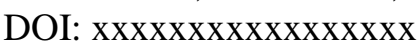

Available online at http:// jurnal.stmikroyal.ac.id/index.php/j-com

wawancara. Teknik observasi dilakukan dengan pengamatan langsung ke Stokis Luxor Kisaran dan melakukan wawancara terhadap salah satu pekerja di Stokis Luxor, sehingga mendapatkan informasi terkait tentang sistem yang ada di Stokis dan informasi data produk yang dijual. Agar penelitian ini selesai dengan baik, maka penulis melakukan teknik pengumpulan data dengan penelitian langsung ke lapangan. Penelitian yang dilakukan yaitu dengan pengambilan data-data yang diperlukan ditempat penelitian.

Tabel 1. Data Produk

\begin{tabular}{|l|l|c|c|c|}
\hline No & Nama Produk & Poin & Harga Member & $\begin{array}{c}\text { Harga } \\
\text { Konsumen }\end{array}$ \\
\hline 1. & $\begin{array}{l}\text { Spirulina } \\
\text { Pacifica 200 Tab }\end{array}$ & 46 & Rp.195.000 & Rp.240.000 \\
\hline 2. & $\begin{array}{l}\text { Spirulina } \\
\text { Pacifica 400 Tab }\end{array}$ & 84 & Rp.345.000 & Rp.425.000 \\
\hline 3. & $\begin{array}{l}\text { Spirulina } \\
\text { Pacifica 800 Tab }\end{array}$ & 156 & Rp.630.000 & Rp.760.000 \\
\hline 4. & $\begin{array}{l}\text { Jelly Gamat 350 } \\
\text { ml }\end{array}$ & 36 & Rp.205.000 & Rp.250.000 \\
\hline 5. & $\begin{array}{l}\text { Jelly Gamat 1000 } \\
\text { ml }\end{array}$ & 36 & Rp.580.000 & Rp.625.000 \\
\hline 6. & Gamat Gel & 24 & Rp.100.000 & Rp.120.000 \\
\hline 7. & Gamat Cream & 24 & Rp.95.000 & Rp.115.000 \\
\hline 8. & $\begin{array}{l}\text { Gamat Aromatic } \\
\text { Massage Oil }\end{array}$ & 12 & Rp.75.000 & Rp.90.000 \\
\hline 9. & $\begin{array}{l}\text { Gamat } \\
\text { Toothpaste }\end{array}$ & 12 & Rp.80.000 & Rp.95.000 \\
\hline 10. & $\begin{array}{l}\text { Gamat Facial } \\
\text { Foam }\end{array}$ & 12 & Rp.60.000 & Rp.70.000 \\
\hline 11. & $\begin{array}{l}\text { Gamat Hand \& } \\
\text { Body Lotion }\end{array}$ & 14 & Rp.75.000 & Rp.90.000 \\
\hline 12. & Vitaluxor & 16 & Rp.140.000 & Rp.170.000 \\
\hline
\end{tabular}

\section{HASIL DAN PEMBAHASAN}

Setelah melalui tahap perancangan, maka sistem yang dibangun telah berhasil menghasilkan sistem yang diperlukan dalam pembelian produk secara online, pendaftaran member bila sudah mencapai minimal poin yang telah ditentukan dengan mengisi username dan password untuk login sebagai member, adanya menu konsultasi untuk calon pelanggan dan untuk member agar memudahkan dalam memberikan pertanyaan ataupun berkonsultasi mengenai produk, kemudian pemberian penilaian/rating dari pembeli dan beserta ulasan dari produk yang telah diterima pembeli. Berikut tampilan halaman utama pada sistem: 
Vol. 1 No. 1, Maret 2021, hlm. 73 - 80

DOI: $\operatorname{xxxxxxxxxxxxxxxxx}$

Available online at http:// jurnal.stmikroyal.ac.id/index.php/j-com

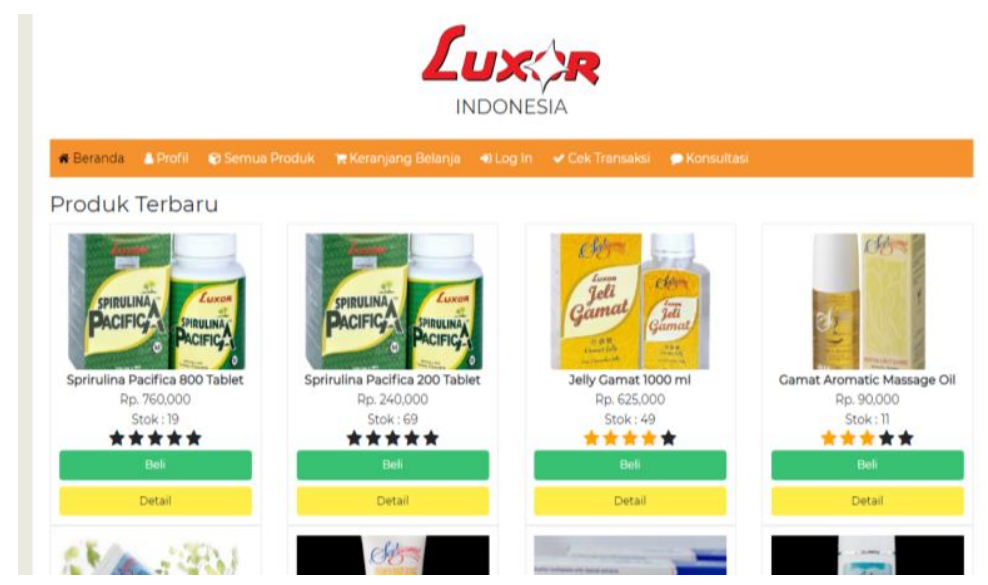

Gambar 1. Halaman Utama

Selanjutnya untuk masuk ke halaman utama admin dan member, admin dan member harus login terlebih dahulu. Berikut halaman login:

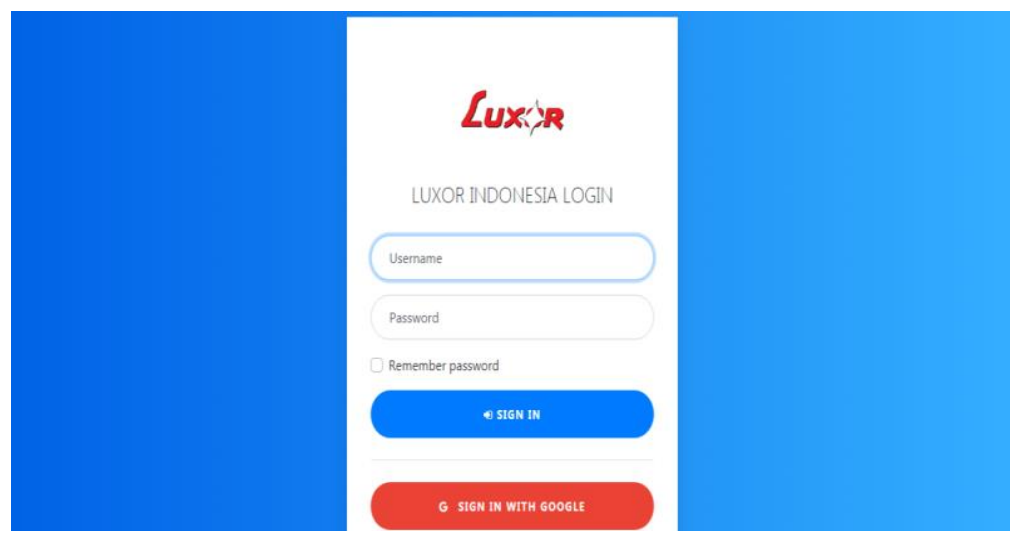

Gambar 2. Halaman Login

Selanjutnya masuk pada halaman admin untuk mengelola data pada sistem. Berikut halaman utama admin :

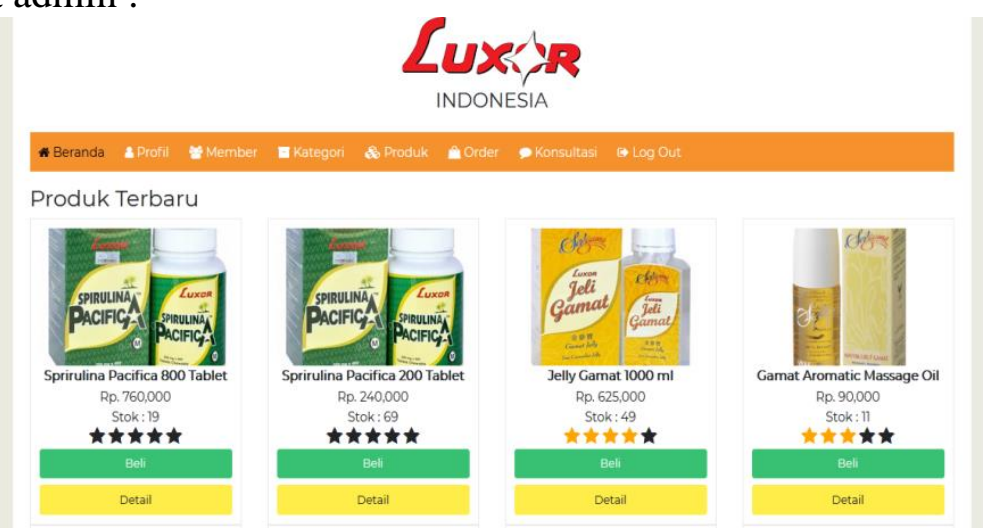

Gambar 3. Halaman Utama Admin 
Vol. 1 No. 1, Maret 2021, hlm. 73 - 80

DOI: $\operatorname{xxxxxxxxxxxxxxxxx}$

Available online at http:// jurnal.stmikroyal.ac.id/index.php/j-com

Untuk mengelola data produk, admin dapat mengupdate, menghapus, dan dapat menambahkan produk serta jumlah stok produk. Berikut halaman produk:

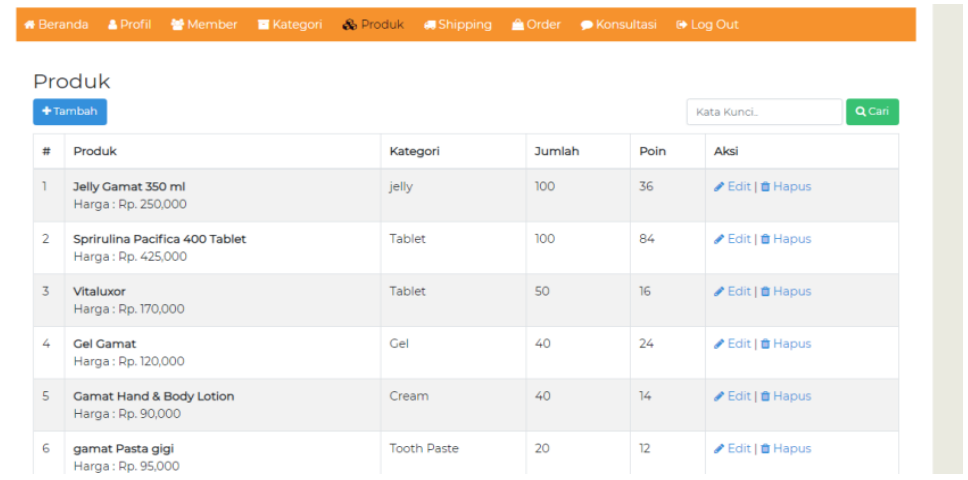

Gambar 4. Halaman Produk

Untuk mengelola kategori dari produk, admin dapat mengupdate, menghapus, dan dapat menambahkan kategori untuk produk. Berikut halaman kategori:

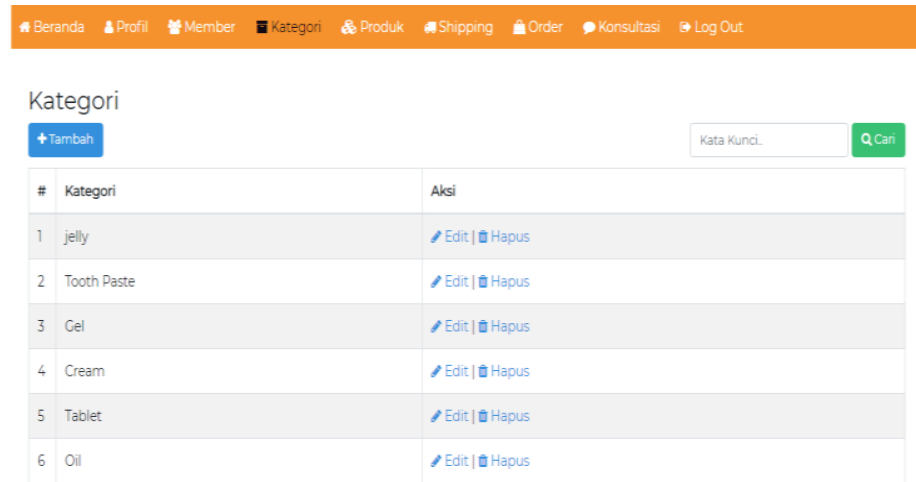

Gambar 5. Halaman Kategori

Selanjutnya untuk melihat detail dari transaksi pembelian, admin akan mengkonfirmasi pembayaran, memberikan pemberitahuan resi barang pada pembeli, dan dapat melakukan cetak laporan pembelian. Berikut halaman order produk:

\section{$\underset{\text { INDONESIA }}{\text { CUXR'PR }}$}

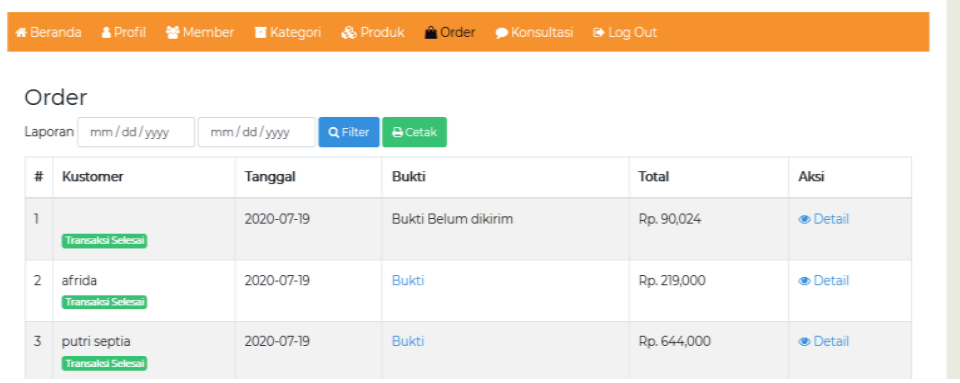

Gambar 6. Halaman Order Produk 
Vol. 1 No. 1, Maret 2021, hlm. 73 - 80

DOI: $\operatorname{xxxxxxxxxxxxxxxx}$

Available online at http:// jurnal.stmikroyal.ac.id/index.php/j-com

Selanjutnya pada halaman keranjang belanja adalah halaman dimana pembeli melakukan pembelian produk. Berikut halaman keranjang belanja:

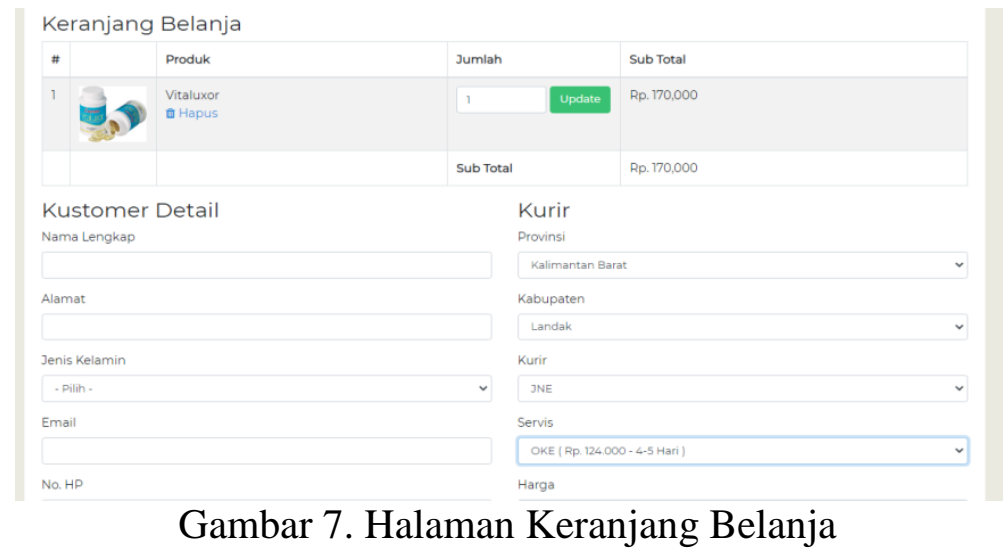

Selanjutnya pada halaman transaksi adalah halaman dimana pembeli melakukan transaksi produk yang dibeli. Berikut halaman transaksi:

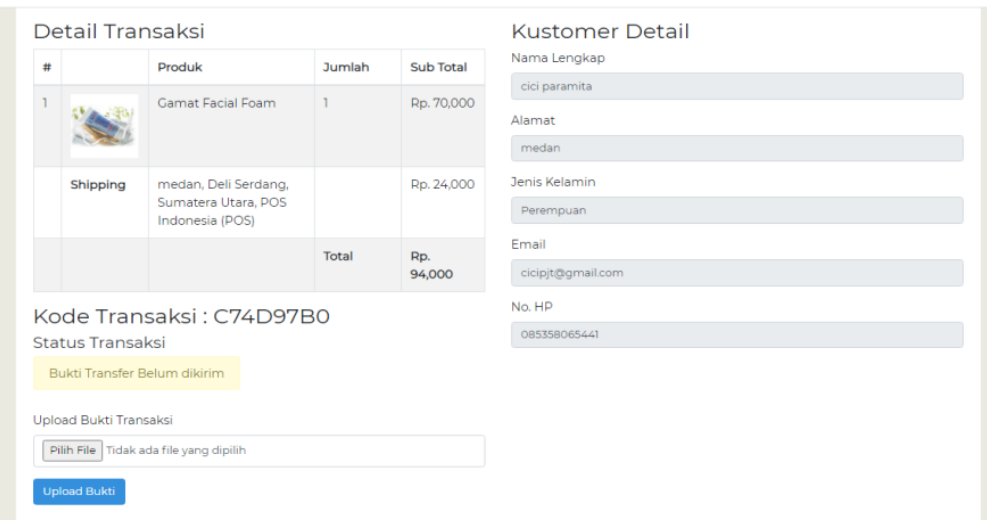

Gambar 8.Halaman Transaksi

Kemudian pada halaman konsultasi adalah halaman dimana calon pelanggan maupun member dapat melakukan konsultasi mengenai produk kepada pihak Stokis. Berikut tampilan halaman konsultasi:

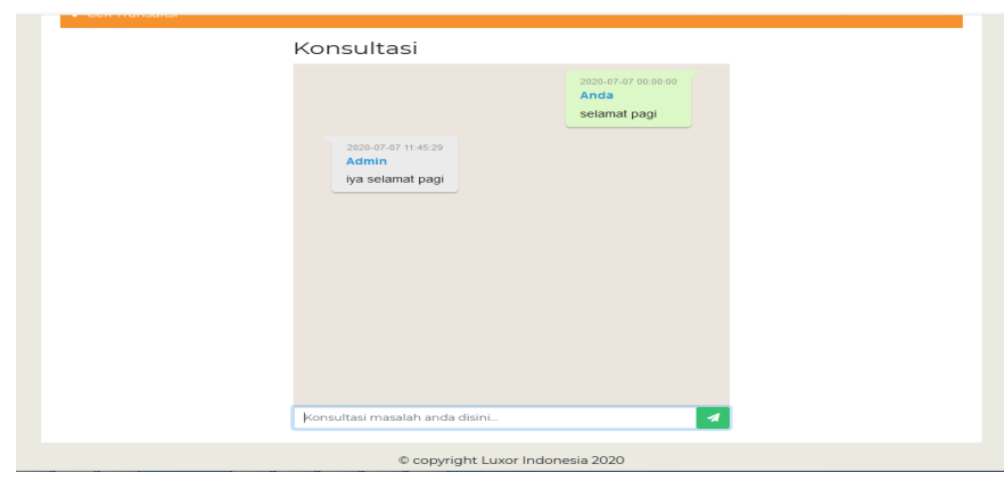

Gambar 9. Halaman Konsultasi 
Vol. 1 No. 1, Maret 2021, hlm. 73 - 80

DOI: $\operatorname{xxxxxxxxxxxxxxxxx}$

Available online at http:// jurnal.stmikroyal.ac.id/index.php/j-com

Selanjutnya pada halaman member merupakan menu halaman yang ada pada admin, dimana pembeli yang sudah mencapai poin akan diarahkan untuk pendaftaran member dan data tersebut akan tersimpan pada halaman member. Berikut halaman member:

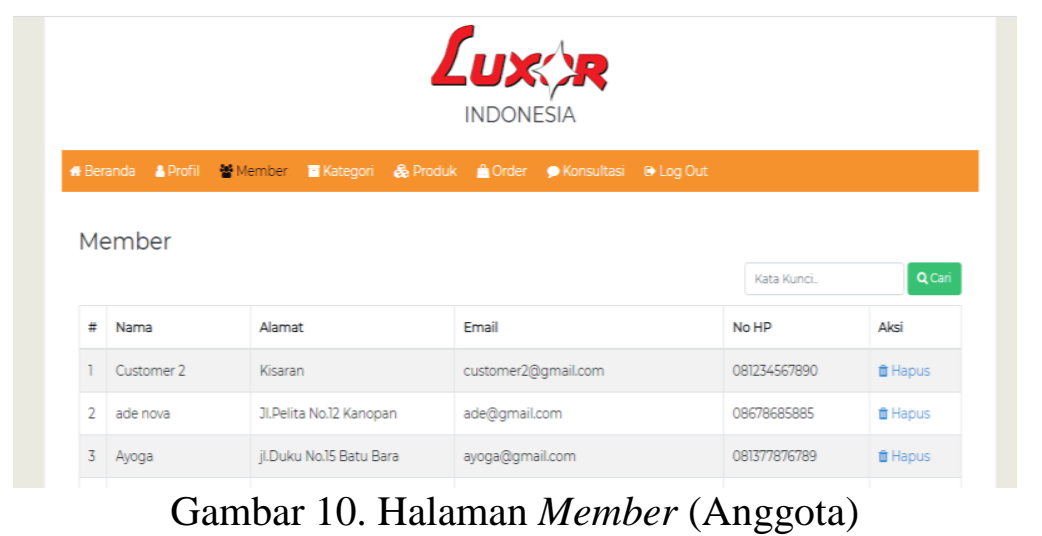

Kemudian untuk halaman cetak laporan terdapat di dalam menu order yang di kelola admin dimana admin dapat melakukan cetak laporan hasil penjualan. Berikut tampilan halaman cetak:

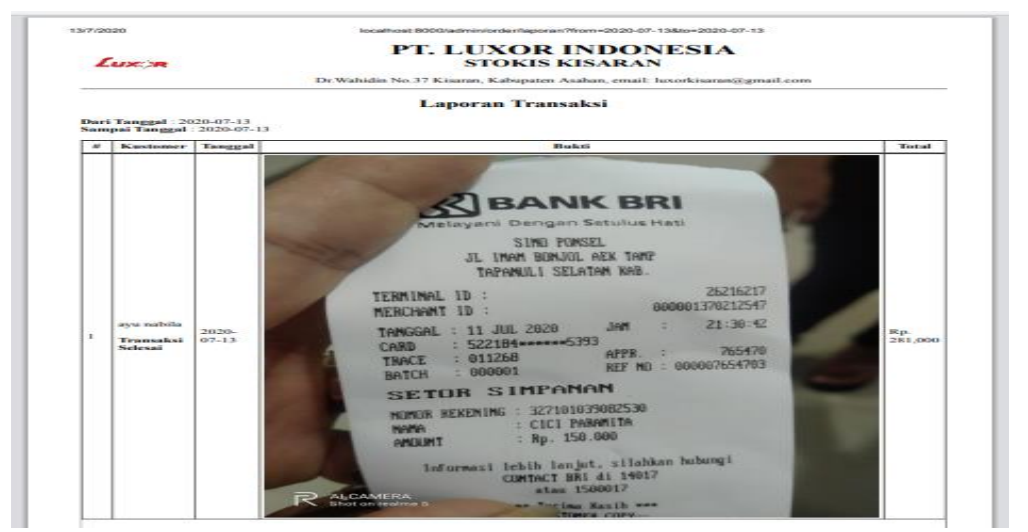

Gambar 11. Halaman Cetak Laporan

\section{SIMPULAN}

Berdasarkan hasil penelitian skripsi dengan judul Penerapan Metode Customer Relationship Management Untuk Stokis Luxor Cabang Kisaran Berbasis Web dapat disimpulkan bahwa sistem ini dibangun dengan bahasa pemrograman $P H P$ dan $M y S Q L$ sebagai databasenya untuk penyimpanan data. Sistem ini juga merupakan sarana dalam menjalin hubungan baik antara pelanggan dengan Stokis. Dalam menjaga hubungan antara pelanggan dan Stokis, Stokis telah menyediakan beberapa fitur untuk memanjakan pelanggannya. Adapun fitur pada sistem yaitu menu konsultasi, pemberian penilaian/rating dan juga komentar/ulasan.Sistem ini dibangun dengan menerapkan 
Vol. 1 No. 1, Maret 2021, hlm. 73 - 80

DOI: $\operatorname{xxxxxxxxxxxxxxxxx}$

Available online at http:// jurnal.stmikroyal.ac.id/index.php/j-com

Metode Customer Relationship Management dimana metode ini merupakan strategi untuk menjaga hubungan yang baik antara pelanggan dengan perusahaan. Dengan diterapkannya Customer Relationship Management pada sistem ini dapat meningkatkan kinerja Stokis, menambah keuntungan, dan dapat menunjang Stokis untuk melakukan pelayanan yang lebih baik.

\section{DAFTAR PUSTAKA}

[1] E. Rahayu, W. M. Kifti, S. Informasi, and S. Royal, "Customer Relationship Management (CRM) Dan Pengaruhnya Terhadap Loyalitas Pelanggan ( Studi Kasus Pada Pelanggan Pt . Cgm Indonesia Kisaran Center )," vol. 9986, no. September, 2018.

[2] A. Syafnur, "Implementasi Penggunaan Web Dengan Metode Customer Relationship Managament Di Tengah Persaingan Antar Pedagang Kopi," J. Teknol. Inf., vol. 3, no. 2, p. 149, 2019, doi: 10.36294/jurti.v3i2.1025.

[3] K. F. Fardhani, I. Rachmawati, and F. S. Prabowo, "Pengaruh Customer Relationship Management ( Crm ) Terhadap Loyalitas Pelanggan English First Samarinda the Effect of Customer Relationship Management ( Crm ) on Customer' S Loyalty of English First Samarinda," e-Proceeding Manag., vol. 3, no. 2, pp. 986-989, 2016.

[4] G. Zulfata, N. H. Wardani, and A. H. Brata, "Pengembangan Electronic Customer Relationship Management ( E-CRM ) Pada Toko Sepatu Aneka Sport Malang Dengan Metode Kerangka Kerja Dynamic CRM," J. Pengemb. Teknol. Inf. dan Ilmu Komput. - Univ. Brawijaya, vol. 2, no. 4, pp. 1419-1427, 2018, [Online].

[5] M. Akif, Y. A. Prasetyo, N. Ambarsari, J. Telekomunikasi, and T. Buah, "PENGEMBANGAN APLIKASI E-CRM BOJANA," vol. 2, no. 1, pp. 10571070, 2015. 